\title{
AN EXTENSION OF THE SIDON-FOMIN TYPE INEQUALITY AND ITS APPLICATIONS
}

\author{
ŽIVORAD TOMOVSKI
}

Abstract. An extension of the Sidon-Fomin type inequality [5] is made by considering the $r$-th derivate of the Dirichlet's kernel $D_{k}^{(r)}$ instead of $D_{k}$. Namely, two different proofs of the following inequality

$$
\int_{0}^{\pi}\left|\sum_{k=0}^{n} \alpha_{k} D_{k}^{(r)}(x)\right| d x=O\left((n+1)^{r+1}\right), \quad\left|\alpha_{k}\right| \leqslant 1 \text { for all } k
$$

are given. Applying the inequality (*) it's shown that the new class $S_{r}$ is a subclass of $B V \cap C_{r}$, $r=0,1,2, \ldots$ where $C_{r}$ is the extension of the Garret-Stanojević class [7] and $B V$ is the class of null sequences of bounded variation. Also, in this paper an extension of the theorem for convergence and integrability for cosine series of a [6] is made by considering the class $S_{r}$, $r=0,1,2, \ldots$ instead of $S$.

Mathematics subject classification (2000): 26D15, 42A20.

Key words and phrases: Sidon-Fomin's inequality, Garret-Stanojević class, Bernstein's inequality, embedding relation.

\section{REFERENCES}

[1] G. A. Fomin, On linear method for summing Fourier series, Mat. Sb. 66 (107) (1964), 144-152 (Russian).

[2] J. W. GarRett, C. S. ReES AND Č. V. Stanojević, $L^{1}$-convergence of Fourier series with coefficients of bounded variation, Proc. Amer. Math. Soc. 80 (1980), 423-430.

[3] J. W. Garrett AND Č. V. Stanojević, Necessary and sufficient condition for $L^{1}$-convergence of trigonometric series, Proc. Amer. Math. Soc. 60 (1976), 68-72.

[4] Sheng Shuyun, The extensions of the theorems of $\check{C}$. V. Stanojević and V. B. Stanojević, Proc. Amer. Math. Soc. 110 (1990), 895-904.

[5] S. SIDON, Hinrehichende Bedingungen für den Fourier-charakter einer trigonometrischen Reihe, J. London. Math. Soc. 14 (1939), 158-160.

[6] S. A. TelyakovsKiI, On a sufficient condition of Sidon for the integrability of trigonometric series, Math. Notes 14 (1973), 317-328 (Russian).

[7] Ž. Tomovski, An extension of the Garrett-Stanojević class, Approx. Theory and its Applications 16 (1) (2000), 46-51, A corrected version is available in the RGMIA Research Report Collection, 3 (4), Article 3, 2000. URL: http://rgmia.vu.edu.au/v3n4.html.

[8] A. Zygmund, Trigonometric Series, Cambridge Univ. Press, 1959. 